\title{
A questionnaire based survey on knowledge, attitude and practices of medical practitioners regarding the prescribing of medications during pregnancy
}

\author{
Gausia Banu ${ }^{1}$, Afzal Khan A. K. ${ }^{2 *}$ \\ ${ }^{1}$ Department of Obstetrics and Gynaecology, MES Medical College, Perintalmanna, Kerala, India \\ ${ }^{2}$ Department of Pharmacology, MES Medical College, Perintalmanna, Kerala, India \\ Received: 15 March 2016 \\ Accepted: 21 March 2016 \\ *Correspondence: \\ Dr. Afzal Khan A. K., \\ E-mail: drafzalkhan4u@gmail.com \\ Copyright: () the author(s), publisher and licensee Medip Academy. This is an open-access article distributed under \\ the terms of the Creative Commons Attribution Non-Commercial License, which permits unrestricted non-commercial \\ use, distribution, and reproduction in any medium, provided the original work is properly cited.
}

\begin{abstract}
Background: Prescribing during pregnancy requires careful estimation of risk/benefit ratio for the mother and her baby. Both, underestimation and overestimation can produce undesirable maternal and fetal outcomes hence the present study was undertaken to assess the knowledge, attitude and practices (KAP) of medical practitioners related to the prescribing of medications during pregnancy.

Methods: A preformed structured questionnaire was administered to 41 medical practitioners. Multiple choice questions (MCQs) and yes/no type questions were used to assess their knowledge. Likert type questions studied their attitude and practices. Their perception of teratogenic risk of medications was evaluated using a visual analogue scale. The data so obtained was analyzed using descriptive statistics.

Results: Completed questionnaires were returned by $76 \%$ of the survey participants. Among whom only $24 \%$ felt highly confident while others were less confident or unsure regarding their prescribing ability during pregnancy. $90 \%$ of the respondents reported that a disease should not be untreated or undertreated due to fear of teratogenicity. $81 \%$ exhibited good knowledge of the FDA pregnancy categorization of drugs and more than $80 \%$ were aware of the teratogenic risk associated with valproic acid, lithium, isotretinoin, warfarin \& thalidomide. The perceived risk of teratogenicity (mean) suggested for them was 33, 52, 52, 43 \& 62 percentage respectively.

Conclusions: Most respondents exhibited a healthy attitude and a fairly sound knowledge, except for their perception of risk associated with individual drugs which was much higher than what is mentioned in the literature. Educational interventions may help to increase the awareness leading to better and confident prescribing.
\end{abstract}

Keywords: Prescribing, Medication, Pregnancy, Medical practitioners

\section{INTRODUCTION}

Pregnancy is a symptom-producing event during which it may be necessary to treat a variety of illnesses. ${ }^{1}$ Treatment instituted to the pregnant mother not only helps in the recovery from maternal illness but also ensures the optimum development of the fetus by preventing embryopathy, preterm births and abortions significantly. ${ }^{2}$
Thankfully most of the available medications are safe to use during pregnancy and at present only around 30-40 drugs are suspected or proven to be human teratogens. ${ }^{3}$ Lack of clear information and incomplete pregnancy risk data in humans makes the clinicians ill equipped to take correct prescribing decisions in this group of patients. As a result the disease is left untreated or undertreated during pregnancy due to the false perception and overestimation of teratogenic risk of medications. Overestimated teratogenic risk is also responsible for unnecessary termination of pregnancies as well. ${ }^{4}$ 
Low adherence to medication is often found in pregnant women due to the perceived safety risks of the prescribed medication and medical practitioners will usually need to carefully explain the important and substantial benefits and small risks of medication not only to ensure patient compliance and good illness control during pregnancy but also to allay the excessive fear of drug teratogenecity. ${ }^{5}$

Hence it is paramount that the medical practitioners understand the principles of teratology and be aware of which medications are safe to use during pregnancy. ${ }^{1}$

The aim of the present study was to assess the medical practitioners' perception of teratogenic risk associated a group of commonly known medications. This study also aimed to assess their knowledge, attitudes and practices (KAP) regarding medication use in pregnancy. The information so obtained will be useful to identify and address the existing gaps and deficiencies in the KAP of the target group and for undertaking future educational interventions for them.

\section{METHODS}

A preformed questionnaire was distributed to 41 medical practitioners having their private practice in a semi urban area within a radius of 20 kilometres from our hospital. Sample was collected by means of convenience sampling. Consent was obtained and anonymity of the respondents was maintained.

The questionnaire we used was adapted from many different sources including Damase-Michel (2007) ${ }^{6}$ and amended to better suit the target group. The reliability of the questionnaire we tested was found to be acceptably good (Chronbach's alpha=0.88). Expert opinion was obtained and the questionnaire was pilot tested in a small sample to confirm its validity.

The questionnaire was divided into three sections: A) Demographic data; B) Knowledge and attitudes towards prescribing medications during pregnancy and C) Risk perception.

The first 4 questions of the questionnaire dealt with demographics, such as age, gender, speciality and length of practice. Knowledge was assessed by five Multiple choice questions (MCQs). Respondents' knowledge was considered "good" if they correctly answered four or more of the five knowledge questions, answering twothree questions correctly was considered "fair" and less than 2 was considered "poor."

Likert-scale questions were used to collect data regarding their attitude and practices. A visual-analogue scale (VAS) was used to evaluate the respondents' perception of teratogenic risk for 20 common medications, where in they were asked to put an arrow on the VAS measuring $20 \mathrm{~cm}$ and delimited by 2 vertical lines, from $0 \%$ to $100 \%$ to indicate the degree of teratogenic risk for each medication $(0 \%$ : indicates no risk i.e. all neonates will be normal, 100\%: indicates all neonates will have a birth defect). The level of the risk was quantified by measuring the distance in millimetres from the $0 \%$ to the mark indicated by the practitioners on the VAS. The mean values of the perceived risk were calculated for each drug.

Descriptive statistics in numbers and percentages were used to describe the results.

\section{RESULTS}

Demographic characteristics of the respondents, their knowledge of teratogenicity associated with medication use as well as their beliefs and practices toward prescribing during pregnancy were analysed. Their perception of degree of teratogenic risk associated with a group of commonly known medications was also measured.

Table 1: Belief and attitude of respondents regarding prescribing during pregnancy.

\begin{tabular}{|llc|}
\hline $\begin{array}{l}\text { Questions } \\
\begin{array}{l}\text { Drugs are the only } \\
\text { proven teratogens }\end{array}\end{array}$ & $\begin{array}{l}\text { Ideal } \\
\text { response }\end{array}$ & $\begin{array}{c}\text { Disagree } \\
\text { ideal response }\end{array}$ \\
\hline $\begin{array}{l}\text { Drugs increase the risk } \\
\text { of birth defects to a very } \\
\text { large extent }\end{array}$ & Disagree & 10 \\
\hline $\begin{array}{l}\text { Most of the presently } \\
\text { available drugs are } \\
\text { unsafe during pregnancy }\end{array}$ & Disagree & 48 \\
\hline $\begin{array}{l}\text { Teratogenicity } \\
\text { associated with drug use } \\
\text { is being over } \\
\text { exaggerated }\end{array}$ & Agree & 43 \\
\hline $\begin{array}{l}\text { An extra caution is } \\
\text { required while } \\
\text { prescribing during } \\
\text { pregnancy }\end{array}$ & Agree & 91 \\
\hline $\begin{array}{l}\text { I am confident about } \\
\text { prescribing drugs during } \\
\text { pregnancy }\end{array}$ & Agree & 24 \\
\hline $\begin{array}{l}\text { I do not take a chance in } \\
\text { prescribing drugs to a } \\
\text { pregnant patient, So I } \\
\text { refer the patient to } \\
\text { another colleague }\end{array}$ & Disagree & 80 \\
\hline $\begin{array}{l}\text { A disease should not be } \\
\text { un treated or under } \\
\text { treated due to the fear of } \\
\text { Teratogenicity }\end{array}$ & Agree & 76 \\
\hline
\end{tabular}

The median age of the medical practitioners was 38 years (range 28-55) and 31\% were females. The mean duration of practice was 9.3 years (range 1-26). 
Of the respondents $77 \%$ of them had the correct knowledge regarding the incidence of birth defects which are known to occur in $2-3 \%$ of all pregnancies, $54 \%$ of them were aware of the fact that $2-3 \%$ of these birth defects are due to drugs. The number proven teratogens are about 30 in number was known to only $60 \%$ of the respondents. $81 \%$ of them exhibited good knowledge of the FDA pregnancy categorization of drugs but only $38 \%$ of them knew that a medication proven as a teratogen in animal studies may not be a confirmed teratogen in humans and that it can be used with caution during pregnancy.

Over all the knowledge was found to be good in $51 \%$ of the respondents, $30 \%$ were fairly knowledgeable and the remaining $19 \%$ exhibited a poor knowledge regarding teratogenecity.

Regarding their beliefs and attitude, see Table 1.

Table 2: Respondents' knowledge of teratogenicity associated with a given list of Drugs.

\begin{tabular}{|llll|}
\hline Drugs & Yes (\%) & No (\%) & No idea (\%) \\
\hline Aspirin & 8 & 92 & 0 \\
\hline $\begin{array}{l}\text { Acetaminophen } \\
\text { (Paracetamol) }\end{array}$ & 0 & 92 & 8 \\
\hline Ibuprofen & 58 & 34 & 8 \\
\hline Corticosteroids & 63 & 37 & 0 \\
\hline Erythromycin & 25 & 67 & 8 \\
\hline Gentamycin & 75 & 17 & 8 \\
\hline Amoxicillin & 0 & 92 & 8 \\
\hline Norfloxacin & 58 & 34 & 8 \\
\hline Diazepam & 62 & 38 & 0 \\
\hline Ranitidine & 8 & 92 & 0 \\
\hline Metoclopramide & 33 & 67 & 0 \\
\hline Domperidone & 33 & 67 & 0 \\
\hline LS COC* & 50 & 25 & 25 \\
\hline SS COC** & 77 & 8 & 15 \\
\hline Carbamazepine & 73 & 14 & 13 \\
\hline Sodium valproate & 87 & 0 & 13 \\
\hline Lithium & 88 & 6 & 6 \\
\hline Iso tretinion & 93 & 7 & 0 \\
\hline Warfarin & 81 & 13 & 6 \\
\hline Thalidomide & 88 & 12 & 0 \\
\hline
\end{tabular}

With respect to their knowledge and perception of teratogenic risk of 20 commonly known medications, Most of the respondents $(92 \%)$ do not associate any teratogenic risk with the use of aspirin, acetaminophen, amoxicillin and ranitidine; similarly $67 \%$ of the respondents do not associate any teratogenic risk with erythromycin, metoclopramide and domperidone. Around $35 \%$ of them believe that corticosteroids, ibuprofen, norfloxacin and diazepam are safe to prescribe during the first trimester. More than $80 \%$ were aware of the teratogenic risk associated with valproic acid, lithium, isotretinoin, warfarin \& thalidomide. The perceived risk of teratogenicity (mean) suggested for these drugs was $33,52,52,43 \& 62$ percentage respectively. For details refer to Tables 2 and 3 .

Table 3: Respondents' perception of teratogenic risk associated with a given list of drugs (A value of $2 \%$ does not differ from the rate of malformation in general population). ${ }^{6}$

\begin{tabular}{|lll|}
\hline Drugs & Perceived (mean) & Literature \\
\hline Aspirin & 7.5 & 2 \\
\hline Acetaminophen & 0 & 2 \\
\hline Ibuprofen & 16.5 & 2 \\
\hline Corticosteroids & 14.33 & 2 \\
\hline Erythromycin & 3.5 & 2 \\
\hline Gentamycin & 27.75 & 2 \\
\hline Amoxicillin & 0 & 2 \\
\hline Norfloxacin & 22.25 & 2 \\
\hline Diazepam & 15.5 & 2 \\
\hline Ranitidine & 7.5 & 2 \\
\hline Metoclopramide & 8.5 & 2 \\
\hline Domperidone & 12.66 & 2 \\
\hline LS COC* & 15 & 2 \\
\hline SS COC** & 17.5 & 2 \\
\hline Carbamazepine & 27 & 6 \\
\hline Sodium valproate & 34 & 10 \\
\hline Lithium & 51.25 & 12 \\
\hline Isotretinion & 62.2 & 25 \\
\hline Warfarin & 44.6 & 30 \\
\hline Thalidomide & 67.83 & 50 \\
\hline
\end{tabular}

\section{DISCUSSION}

Prescribing in pregnancy has remained a problem to practising physicians over the years. ${ }^{7}$

Our study aimed at assessing the medical practitioners' knowledge of teratogenicity associated with medication use as well as their beliefs and practices regarding drug prescribing during pregnancy.

The knowledge was found to be fairly good in $81 \%$ of study participants. The concept of teratogenicity was well understood and the practitioners were well informed about the risk in the general population. However $50 \%$ of the practitioners wrongly implicated the drugs to be responsible for most cases of teratogenicity. Product labelling or package inserts provided by the manufacturers give a wrong impression that most medications have an associated teratogenic risk as many medications are labelled "not to be used in pregnancy unless potential benefits outweigh the risks," due to their scarcity of sufficient evidence in pregnant women to pronounce them "safe," may be responsible for such misinformation. ${ }^{8}$ Moreover the drug risk classification in many countries tend to convey a high risk for most drugs ${ }^{9}$ like the US Food and Drug Administration (FDA) which categorizes drugs as A, B, C, D or X based on the level of 
animal and human evidence limits the number of drugs that are rated as Category $\mathrm{A}$, due to the lack of wellcontrolled studies in pregnant women, which may not always be ethically or financially feasible gives the impression that only very few drugs have no risk. ${ }^{10}$

In order to overcome the limitations of the existing pregnancy labelling system, the FDA has been developing a new regulation since 1997. The proposed regulation would replace the letter categories with more detailed, narrative descriptions. Information on fertility, pregnancy and breastfeeding would be included. ${ }^{11}$

In the present study, $80 \%$ of the practitioners were aware of the FDA pregnancy categorization of drugs but only $38 \%$ of them knew the practical significance of correlating teratogenic data from animal studies to humans. Even though animal experiments have provided considerable information concerning the teratogenic effects of drugs, unfortunately these experimental findings cannot be extrapolated to humans because of interspecies variability. ${ }^{12}$

Prescribing medications during pregnancy requires the practitioners to be confident which can have a positive influence on the patient's trust and compliance. Confidence was expressed by only $24 \%$ of our respondents. $20 \%$ of the study participants did not want to take any chances and hence their usual practice was to refer the patient to another colleague. The lack of confidence and not taking the responsibility to prescribe to pregnant mothers may be due to insufficient initial training as students or residents about drug use in pregnancy. Fear of litigation or law suits may also be another reason. ${ }^{4,6}$

The individual teratogenic risk of the given list of drugs is usually low or negligible, except for thalidomide, retinoids, warfarin, carbamazepine and valproic acid. Most of the practitioners over perceived the teratogenic risk, at the same time a small number were unaware of teratogenicity associated with these proven teratogens.

Underestimation of teratogenic risk can increase the fetal defects at the same time misinformed treatment providers who overestimate the teratogenic risk associated with medications may provide wrong counselling to women who mainly depend on the physicians for their information leading to decreased compliance to treatment, inadequate treatment of maternal disease or termination of otherwise wanted pregnancy. ${ }^{13}$

Our results concur with that of Damase-Michel, et al who had reported a very high teratogenic risk perception of health care professionals in Midi-Pyrenees area in France for similar drugs and whose questionnaire and list of drugs, we adapted to suit our study requirement. ${ }^{6}$ When compared to their study subjects which comprised of both general practitioners and community pharmacists the perception of teratogenic risk was much lower in our study participants. This may be due very high teratogenic risk perception exhibited by the community pharmacists.

Our study has some limitations. Our survey sample was a convenience, purposely selected cluster sample and possibly was under representative and small. Nevertheless our study participants exhibited similar higher perception of teratogenic risk as previous studies. $^{6,14}$

Teratogen information service (TIS) is an important component for assisting the physicians. ${ }^{15}$ Unfortunately, physicians in developing countries, do not have access to such information.

Establishing TIS, imparting adequate training to medical students and educating the practicing physicians through continuing medical education programs may be undertaken to address the issue of lack of confidence. Simple hand-outs which provide unambiguous information may be useful for time constrained medical practitioners.

Obtaining adequate information on drug safety during pregnancy is very essential and pregnancy registries are doing the same by undertaking follow up studies to learn what exposures occur during the course of pregnancy and about the health of new-born.

Until reliable and sufficient data is acquired and new guidelines released, the health care practitioners have to do the best they can in evaluating all the existing options in regards to medication use during pregnancy.

\section{ACKNOWLEDGEMENTS}

The authors gratefully acknowledge the participation, and cooperation of the medical practitioners for the conduct of their study.

\section{Funding: No funding sources \\ Conflict of interest: None declared \\ Ethical approval: Not Required}

\section{REFERENCES}

1. Yankowitz J, Niebyl JR. Drug Therapy in Pregnancy. $3^{\text {rd }}$ ed. USA: Lippincott Williams \& Wilkins; 2001

2. Sharma R, Kapoor B, Verma U. Drug utilization pattern during pregnancy in North India. Indian $\mathrm{J}$ Med Sci. 2006;60:277-87.

3. Cunningham FG, Leveno KJ, Bloom SL, Hauth JC, Rouse DJ, Spong CY. Teratology and medications that affect the Fetus. In Williams Obstetrics. $23^{\text {rd }}$ edn. U.S.A: McGraw-Hill. 2011.

4. Banhidy F, Lowry RB, Czeizel AE. Risk and benefit of drug use during pregnancy. Int $\mathrm{J}$ Med Sci. 2005;2:100-6. 
5. Yawn B, Knudtson M. Treating asthma and comorbid allergic rhinitis in pregnancy. J Am Board Fam Med. 2007;20:289-98.

6. Damase-Michel C, Pichereau J, Pathak A, Lacroix I, Montastruc JL. Perception of teratogenic and foetotoxic risk by health professionals: a survey in midi-pyrenees area. Pharmacy Practice. 2008;6:15-9.

7. Chin RKH, Lao TTH, Chang AMZ. Drug prescribing in pregnancy - a survey among general practitioners in Shatin. J Hong Kong Med Assoc. 1986;38:27-9.

8. Ratnapalan S, Bona N, Chandra K, Koren G. Physicians' perceptions of teratogenic risk associated with radiography and ct during early pregnancy. AJR. 2004;182:1107-9.

9. Schaefer C. Drug safety in pregnancy: Utopia or achievable prospect? Risk information, risk research and advocacy in teratology information services. Congenital Anomalies. 2011;51:6-11.

10. Chambers CD, Polifka JF, Friedman JM. Drug Safety in pregnant women and their babies: ignorance not bliss. Clin Pharmacol Therap. 2008;83:181-3.
11. Meadows M. Pregnancy and the drug dilemma. FDA consumer magazine. US Food and Drug Administration. 2001.

12. Peters PWJ. Risk assessment of drug use in pregnancy: prevention of birth defects. Ann Ist Super. Sanita. 1993;29:131-7.

13. Goodwin J, Rieder S, Rieder MJ, Matsui D. Counseling regarding pregnancy-related drug exposures by family physicians in Ontario. Can $\mathbf{J}$ Clin Pharmacol. 2007; 14:e58-69.

14. Koren G, Levichek Z. The teratogenicity of drugs for nausea and vomiting of pregnancy: perceived versus true risk. AmJ Obstet Gynecol. 2002;186:248-52.

15. Einarson A, Park A, Koren G. How physicians perceive and utilize information from a teratogen information service: the mother risk program. BMC Med Edu. 2004;4:6.

Cite this article as: Banu G, Khan AAK. A questionnaire based survey on knowledge, attitude and practices of medical practitioners regarding the prescribing of medications during pregnancy. Int J Reprod Contracept Obstet Gynecol 2016;5:984-8. 